\title{
Sociodemographic Factors and its Impact on Health Related Quality of Life (HRQoL) among Adult Asthma Patients in a Private Specialist Hospital in Malaysia
}

\author{
Hanish Singh Jayasingh Chellammal', Dhivyatharishini Arumugam ', Bama VV Menon', Shashidharan Menon Muralidharan Menon', \\ Shafeeq Bin Mohd Faizal' \\ Unit of Pharmacology, School of Pharmacy, KPJ Healthcare University College, Kota Seriemas, Nilai, Negeri Sembilan, MALAYSIA. \\ ²Department of Clinical Pharmacy, KPJ Seremban Specialist Hospital, Lot 6219 and 6220, Jalan Toman 1, Kemayan Square, Seremban, Negeri Sembilan, MALAYSIA.
}

\begin{abstract}
Objectives: The present study aimed to explore the factors associated to asthma and HROoL of patients. Asthma and Chronic obstructive pulmonary diseases implicate severe restrictions on physical, social and emotional aspects of the patients' life. Health-related quality of life (HROoL) is a patient derived measurement that defines the functional effects of illness and treatment, as perceived by the patient. Methodology: A descriptive cross-sectional study comprised of 100 asthma patients sampled in the outpatient department of KPJ Seremban Specialist Hospital. Mini-Asthma Quality of Life Questionnaire (Mini-AQLQ) with two sections was used as instrument in this study. The first section comprises six (6) Sociodemographic questions and the second section comprises fifteen (15) questions of HRQoL covering four main domains such as emotional, activity, symptoms and environmental. Results: The sociodemographic factor that correlated positively with HRQoL in all domains of the AQLO was the higher education level of patients. Factors that negatively influenced the entire AQLO domain were the older age of the patients and lower occupation status. The most affected domain of AQLO due to asthma is the emotional
\end{abstract}

domain and the least affected domain is the activity domain. Conclusion: This study represents that age decreased the HRQoL of patients and concluded that higher education level contributes to better HROLL scores and implies that higher education plays a pivotal role in $\mathrm{HRQOL}$ and we believe that it can be improve by reinforcing Health education.

Key words: Bronchial Asthma, Health related quality of life, Sociodemographic factors, Symptoms domain, Activity domain, Emotional domain, Environmental domain.

\section{Correspondence}

Dr. Hanish Singh Jayasingh Chellammal,

Unit of Pharmacology, School of Pharmacy, KPJ Healthcare University College, Kota Seriemas, Nilai, Negeri Sembilan-71800, MALAYSIA.

Phone: +601115096775

Email: hanish@kpjuc.edu.my

DOI: 10.5530/jyp.2019.11.83

\section{INTRODUCTION}

Chronic disease such as asthma is common in Malaysia and many other developing countries. According to the National Asthma Education and Prevention Program, asthma is defined as a chronic inflammatory disorder of the airways in which many cells and cellular elements play a role, in particular, mast cells, eosinophils, T lymphocytes, macrophages, neutrophils and epithelial cells. In susceptible individuals this inflammation causes recurrent episodes of wheezing, breathlessness, chest tightness and coughing, particularly at night or in the early morning. ${ }^{1}$ These episodes are usually associated with widespread but variable airflow obstruction that is often reversible either spontaneously or with treatment. The inflammation also causes an increase in existing bronchial hyperresponsiveness to a variety of stimuli. ${ }^{2}$

According to the scale of problem by World Health Organization (WHO), the asthmatic patients is approximately 235 million $^{3}$ and is expected to raise globally as the mortality rate caused by this incidence have reached over 180,000 in a year. In Malaysia, the findings of from third national health and morbidity survey conducted by the Ministry of Health Malaysia in 2006, states that the total prevalence of asthma in Malaysia was $7.1 \%$ and the prevalence of adult asthma was $4.1 \%$. The highest prevalence were among Malays (67\%), followed by Chinese (73\%), Indians (12.9\%) and others (10\%). In 2016 the health ministry's pulmonology division stated that only $6 \%$ of asthmatics were in control out of 2 million asthmatic patients in Malaysia and is due to poor compliance with lack of awareness. ${ }^{4}$ Prevalence studies by sociodemographic factors in Malaysia shows that adult asthma by gender indicated a higher number in females (58.4\%) compared to male (41.6\%). In the case of age group, the highest prevalence was among the age group of group 20-24 years old (11.6\%), followed by the age group $45-49$ years old (10.3\%), whereas the age group of above 60 years old only accounted for $2.1 \%$. In the category of education level, the prevalence of adult asthma was highest among secondary education level (47.5\%), followed by primary education level $(30.7 \%)$ and no education level (13.2\%). Those with tertiary education level only accounted for $(8.6 \%){ }^{5}$

Asthma is a well-known to negatively influence the individuals of all ages. Asthma patients often grumbles about the effects on their social, physical and psychological domains of life quality. ${ }^{6}$ The modern treatment objective for asthma is to attain and preserve asthma control in a longterm perspectives including improvement of Health Related Quality of Life (HRQL) apart from managing clinical manifestations. ${ }^{7}$ In regards to this, the HRQoL concept was initiated into clinical and medical practice in 1990s'. HRQoL is described as patient perception on effects of the disease and treatment management. ${ }^{8}$ HRQoL consists of items in aspects of clinical, medical condition, the psychological condition, physical fitness of patients, emotional status, social status and wellbeing. These significantly accountable for the health burden as the physical, psychological and social consequences of asthma and have 
impact on the quality of life of affected individuals in long term. ${ }^{9,10}$ It's also known that patient's personality plays key role in medication adherence and improved HRQoL. ${ }^{11}$ Besides numerous data in HRQoL, limited reports have been identified in Malaysia with the influence of sociodemographic factors of the patients on their quality of life and the present study was designed to determine the influence of sociodemographic factors related to HRQoL of asthma using specific and generic questionnaires in Malaysia population. This study enables the recognition of various factors that might affect the various domains of HRQoL of asthma patients such as symptoms domain, environmental domain, activity domain and emotional domain. The influence of sociodemographic factors (age, gender, marital status, education level and occupation), clinical, environmental and personal characteristics of the patients are often overlooked in evaluating the health related quality of life.

\section{METHODOLOGY}

\section{Study design and Sampling}

The study is descriptive cross sectional design evaluating the influence of sociodemographic factors on the HRQoL among adult asthma patients in KPJ Seremban Specialist Hospital. The target population for this study was the asthma patients who attending outpatient pharmacy to collect their medications and also to receive counselling. The respondents selected were not in critical condition and able to present themselves in outpatient pharmacy department. The respondents were informed about the purpose of the research with informed consent and provided an opportunity to ask questions and withdraw from the study without any consequences. The sample size was calculated considering the outpatient prescriptions. The outpatient pharmacy department receives around 100 prescriptions per day and the prescriptions for asthma medication were estimated to be approximately 7 prescriptions per day and are calculated for an additional of $10 \%$ of sample size needed to compensate if there is any withdrawal due to incomplete data in the data collection form. A total of 120 asthma patients, age ranged 21 to $60(38.5 \pm 12.3)$ were identified during the data collection period and study included 100 asthma patients' (27 male patients and 73 female patients) response after excluding incomplete questionnaires. The age range was from 21 to 60 years old. The sample size required for this study was determined by the formula ${ }^{12} n=\mathrm{Z} 2 \mathrm{P}(1-\mathrm{P}) / \mathrm{d} 2$. Where $n=$ required sample size, $\mathrm{Z}=$ value - confidence level at $95 \%$ (standard value of 1.96 ), $p=$ estimated number of asthma patients, $d=$ precision - margin of error at $5 \%$ (standard value of 0.05 ).

\section{Inclusion and exclusion Criteria}

Patients with a confirmed diagnosis of bronchial asthma aged 21 to 60 years old were included. Pregnant patients, patients with co-morbid metabolic diseases, patients underwent surgery, children and incomplete response sheet were considered for exclusion in the research. KPJ Clinical Information System (KCIS) was used in collecting the prescriptions. The questionnaire distribution was performed at the dispensing counter and also at the waiting area of the outpatient pharmacy department.

\section{Study Instrument}

The tools used to obtain data were a set of questionnaire consist of two sections, such as sociodemographic data of the patients and health related quality of life (HRQoL). Sociodemographic information were collected from all patients, including age, gender, race, occupation status, education level and marital status, whereas the Mini-Asthma Quality of Life Questionnaire (Mini-AQLQ) developed by Juniper EF were used to evaluate the health related quality of life of asthma patients. ${ }^{13}$ The Mini-AQLQ consists of 15 items that are separated into four domains with questions. These are activity limitation domains (4 items), emotional function domain (3 items), symptoms domain (5 items) and environmental stimuli domain ( 3 items). All items are equally weighted. The patients will evaluate their experience with asthma condition in the previous 2 weeks by using a 7-point scale. If the patient experiences no impairment, the score of 7 will be given whereas if the patient experience severe impairment the score of 1 will be given. On the other hand, the middle score of 4 indicates that the patient only experience moderate impairment due to asthma.

\section{Measurements}

\section{Correlation and mean difference between socio demographic factors and the domains of AQLQ}

A series of correlation between the sociodemographic factors and the domains of AQLQ was checked for further exploring its relationship with the quality of life of asthma patients. In this study, the sociodemographic factors were associated as the independent variables whereas the AQLQ domains as the dependent variables. The hypothesis for testing the correlation between the variables is: $\mathrm{HO}$ : Indicates no significant correlation between the sociodemographic factors and the domains of AQLQ. HA Indicates a significant correlation between the sociodemographic factors and the domains of AQLQ. The difference in means from different group of sociodemographic factors were determined in relation to all the domains of AQLQ and is mentioned below such as: (i) Symptoms domain (ii) Activity domain (iii) Emotional domain (iii) Environmental domain. The hypothesis for testing the equality of means between the variables is: $\mathrm{HO}$ - indicates a presence of equal means between the groups of sociodemographic factors for the domains of AQLQ. HA: indicates no equal means between the groups of sociodemographic factors for the domains of AQLQ.

\section{Data analysis}

All data were analyzed by SPSS software system (Version 20.0). Statistical Analysis for Quantitative characteristics (AQLQ) involved the calculation of basic statistics, for example the mean, median, mode and standard deviation. $t$-test for independent variables was used to verify the significance differences between quantitative variables with normal distribution in two groups (sex). In the case where the distribution of a given variable significantly differed from normal or by variance, the non-parametric Mann-Whitney U-test was used. Other than that, if the variable distribution in all groups were not significantly different from normal, the nonparametric Kruskal-Wallis test was used for skewed distribution (e.g., education level and occupation status). Pearson's or Spearman's linear correlation ( $r_{s}$ or $r$ ) were used to determine the strength of correlation between two quantitative variables. Numbers (n) and percentages (\%) were calculated for qualitative variables. Chi-square test was used to verify the independence of qualitative variables. All the data was presented in the form of tables and graphs. A p-value of less than 0.05 was considered statistically significant.

\section{RESULTS}

\section{Mean score of each domains of AQLQ}

The total mean score was calculated to determine the most affected domain of the AQLQ due to asthma. The domain with the highest total mean score is the activity domain (3.73) followed by environmental domain (3.06) and symptoms domain (2.90) whereas the domain of emotional only accounted for (2.75). From this total mean score, it can be concluded that higher the total mean score, the better quality of life from the aspect of each domain, whereas the lower total mean score, the lower quality of life, indicating that it is the most affected. 
domain due to asthma. In this case, the most affected domain is the emotional domain of AQLQ.

\section{Sociodemographic factors affecting the HRQoL as measured using AQLQ}

As shown in Table 1, the percentage of adult asthma by gender showed a higher number in females, $73 \%$ compared to male, $27 \%$. In the case of age group, the highest prevalence was among 31-40 years old, $38 \%$ followed by 41-50 years old, 21-30 years old, 18\%, whereas the age group of 51-60 years old only accounted for $15 \%$. Besides that, in the case of occupation status, the highest percentage was among employed patients $45 \%$, followed by unemployed patients $25 \%$ and students $13 \%$. The last sociodemographic category, marital status shows a high percentage of married patients $83 \%$, followed by divorced $11 \%$ and single $6 \%$.

\section{Mean difference between Sociodemographic factors and various domains of $A Q L Q$}

Age

As shown in Table 2, the difference between the mean ranks of four various age groups $(21-30,31-40,41-50,51-60)$ on the symptoms domains of AQLQ exhibited a significant difference $(P=0.003)$ and stating that age has a significant effect on the symptoms domain of AQLQ. The pairwise differences among the four groups, indicated significant difference $(p<0.05)$ between the age group of $51-60$ and $21-40(p=0.002)$ and also 51-60 and 31-40 ( $p=0.033)$. The mean rank suggests that the symptoms domain decreases the quality of life on the age group 51-60

\section{Table 1: Sociodemographic characteristics of asthma patients.}

\begin{tabular}{|c|c|c|c|}
\hline Sociodemographic data & Female (n) & Male (n) & Total \\
\hline Gender & 73 & 27 & 100 \\
\hline \multicolumn{4}{|l|}{ Age } \\
\hline $21-30$ & 15 & 3 & 18 \\
\hline $31-40$ & 28 & 10 & 38 \\
\hline $41-50$ & 21 & 8 & 29 \\
\hline $51-60$ & 9 & 6 & 15 \\
\hline \multicolumn{4}{|l|}{ Race } \\
\hline Malay & 31 & 10 & 41 \\
\hline Chinese & 19 & 11 & 30 \\
\hline Indian & 20 & 6 & 26 \\
\hline Others & 3 & 0 & 3 \\
\hline \multicolumn{4}{|l|}{ Education Level } \\
\hline Primary & 9 & 6 & 15 \\
\hline Secondary & 22 & 6 & 28 \\
\hline College/University & 42 & 15 & 57 \\
\hline \multicolumn{4}{|l|}{ Occupation Status } \\
\hline Student & 11 & 2 & 13 \\
\hline Employed & 45 & 17 & 45 \\
\hline Unemployed & 17 & 8 & 25 \\
\hline \multicolumn{4}{|l|}{ Marital Status } \\
\hline Single & 5 & 1 & 6 \\
\hline Married & 63 & 20 & 83 \\
\hline Divorced & 5 & 6 & 11 \\
\hline Widowed & 0 & 0 & 0 \\
\hline
\end{tabular}

and which is greater compared to other age group. In the activity domains of AQLQ, there is a significant difference $(p=0.001)$ between the mean ranks of different age groups. The pairwise differences among the four groups exhibited significant difference between the age group of 51-60 and 21-40 ( $p=0.005), 51-60$ and $31-40(p=0.002), 41-50$ and 21-30 $(p=0.001)$ and $41-50$ and $31-40(p=0.001)$ respectively. This mean rank suggests that for activity domain, the decrease in quality of life for the age group 41-50 is greater compared to other age groups. In the emotional domains of AQLQ the difference between the mean ranks of four age groups $(21-30,31-40,41-50,51-60)$ indicates a significant difference $(p=0.011)$ and influences the emotional domain of AQLQ. In the mean rank of emotional domain, the decrease in quality of life for the age group 51-60 is greater compared to other age groups? The mean ranks of four different age groups (21-30, 31-40, 41-50, 51-60) on the environmental domains of AQLQ indicates that there is a significant difference $(p=0.015)$ and exhibits the influence on the environmental domain in AQLQ. It's observed that there is a significant difference $(p<0.05)$ between the age group of 51-60 and 21-30 $(p=0.040)$ and also 41-50 and 21-30 ( $p=0.023)$. The mean rank suggests that for environmental domain, the decrease in quality of life of the age group 51-60 is greater compared to other age groups.

\section{Education level}

The mean ranks of three levels of educational groups (Primary, Secondary and College/University level) on the symptoms domains of AQLQ indicated a significant $(p=0.001)$ difference. The mean ranks suggest a better quality of life in the highly literate group compared to other education level groups. It's indicated that there is no significant difference between the mean of difference by gender, race, occupational status and marital status which reveals that the quality of life in the symptoms domain is not affected by sociodemographic factors. In activity domain, there is a significant difference $(p=0.002)$ between the mean ranks of different education level groups, stating that education level plays a key role in activity domain of AQLQ. The pair wise differences was evidenced significantly $(p<0.05)$ between the group of secondary and college/ university $(p=0.005)$ and suggests a lower quality of life in other education level groups of College/university. In the emotional domains of AQLQ, there is a significant difference $(p=0.015)$ between the mean ranks in different educational groups. It was also found that there was a significant difference $(p<0.05)$ between the group of Primary - Secondary $(p=0.048)$ and Secondary - College/university $(p=0.013)$. This mean rank suggests a lower quality of life in the Primary group compared to other educated groups. In the environmental domains, there was a significant difference $(p=0.05)$, stating that education level have influence on AQLQ. The comparison of primary and secondary education level exhibited a significant $(p<0.05)$ difference, states that secondary education influences the better quality of life. It was also observed that the quality of life in the environmental domain is not affected by other criteria such as groups of gender, race, occupation status and marital status.

\section{Occupational Status}

The difference between the mean ranks of three groups of occupational status and its influence in the activity domain and emotional domains of AQLQ (student, employed and unemployed) indicated a significant difference $(p=0.001)$; Table 2 . The pair wise evaluation among the three groups in regards with emotional and activity domain indicated a significant difference in employed - unemployed $(p=0.001)$ and employed student $(p=0.001)$. 
Table 2: Mean differences between socio demographic factors and various Domains.

\begin{tabular}{|c|c|c|c|c|c|c|c|c|c|}
\hline \multirow[b]{2}{*}{$\begin{array}{l}\text { Socio demographic } \\
\text { factors }\end{array}$} & \multirow[b]{2}{*}{$\mathbf{N}$} & \multicolumn{2}{|c|}{ Symptoms Domain } & \multicolumn{2}{|c|}{ Activity Domain } & \multicolumn{2}{|c|}{ Emotional Domain } & \multicolumn{2}{|c|}{ Environmental Domain } \\
\hline & & Mean Rank & $p$-value & Mean Rank & $p$-value & $\begin{array}{l}\text { Mean } \\
\text { Rank }\end{array}$ & $p$-value & Mean Rank & $p$-value \\
\hline Age & 18 & 65.31 & 0.003 & 66.61 & 0.001 & 68.92 & 0.011 & 67.69 & 0.015 \\
\hline $21-30$ & 38 & 52.92 & & 63.83 & & 48.08 & & 52.14 & \\
\hline $31-40$ & 29 & 49.47 & & 32.12 & & 49.14 & & 42.84 & \\
\hline $41-50$ & 15 & 28.60 & & 32.93 & & 37.17 & & 40.50 & \\
\hline \multicolumn{10}{|l|}{$51-60$} \\
\hline Gender & 27 & 43.11 & 0.118 & 43.70 & 0.149 & 46.83 & 0.436 & 51.19 & 0.885 \\
\hline Male & 73 & 53.23 & & 53.01 & & 51.86 & & 50.25 & \\
\hline \multicolumn{10}{|l|}{ Female } \\
\hline Race & 41 & 52.16 & 0.167 & 43.20 & 0.123 & 50.22 & 0.545 & 45.85 & 0.532 \\
\hline Malay & 30 & 41.77 & & 59.38 & & 55.27 & & 55.55 & \\
\hline Chinese & 26 & 55.79 & & 50.88 & & 47.33 & & 47.33 & \\
\hline Indians & 3 & 69.33 & & 58.17 & & 34.17 & & 34.17 & \\
\hline \multicolumn{10}{|l|}{ Others } \\
\hline Education Level & 15 & 22.40 & 0.001 & 60.07 & 0.002 & 30.80 & 0.015 & 34.93 & 0.047 \\
\hline Primary & 28 & 39.52 & & 62.86 & & 52.86 & & 57.50 & \\
\hline Secondary & 57 & 63.29 & & 41.91 & & 54.53 & & 51.16 & \\
\hline \multicolumn{10}{|l|}{ College/University } \\
\hline Occupation Status & 13 & 43.12 & 0.506 & 68.42 & 0.001 & 51.35 & 0.001 & 66.50 & 0.098 \\
\hline Student & 62 & 52.81 & & 38.02 & & 42.16 & & 47.96 & \\
\hline Employed & 25 & 48.62 & & 72.14 & & 70.74 & & 48.48 & \\
\hline \multicolumn{10}{|l|}{ Unemployed } \\
\hline Marital Status & 6 & 37.17 & 0.100 & 38.75 & 0.554 & 65.25 & 0.409 & 40.50 & 0.644 \\
\hline Single & 83 & 53.29 & & 51.60 & & 49.23 & & 50.79 & \\
\hline Married & 11 & 36.73 & & 48.64 & & 52.00 & & 53.77 & \\
\hline Divorced & & & & & & & & & \\
\hline
\end{tabular}

Note: $p<0.05$ indicates the significant difference between the sociodemographic factors and various domains performed by Kruskal Wallis test

\section{Influence of other factors and various domains of AQLQ}

The mean ranks suggest a lower quality of life in the employed group compared to other occupation status groups and there is no significant difference between the gender, race and marital status.

\section{Correlation between the factors of HRQoL in various domain of the AQLQ}

Table 3 shows that there is a significant negative correlation found between HRQoL in the all the four domains indicating HRQoL domains decreases as the age of patients increases. The significant difference in symptoms domain $\left(r_{s}=-0.339, p=0.001\right)$, Activity domain $\left(r_{s}=-0.517\right.$, $p=0.01)$, emotional domain $\left(\mathrm{r}_{\mathrm{s}}=-0.277, p=0.005\right)$ and environmental domain $\left(r_{s}=-0.310, p=0.002\right)$ were observed. However, it increases significantly as the education level of the patient increases and a significant positive correlation $\left[\left(\mathrm{r}_{\mathrm{s}}=0.546, p=0.001\right) ;\left[\left(\mathrm{r}_{\mathrm{s}}=0.221, p=0.027\right)\right]\right.$ was found respectively in symptoms domain and emotional domain. The HRQoL in emotional domain of AQLQ also increases significantly as the occupation status of the patient increases. This is also because a significant positive correlation was found between quality of life of emotional domain of AQLQ and occupation status of the patient $\left(r_{s}=0.305, p=0.002\right)$. In case of symptoms there is no significant correlation was observed respective to gender, race, occupation status and marital status.

\section{DISCUSSION}

HRQoL of asthma patients is considered as major issue and it's on discussions and research in the last two decades, forecasting and assessing the control on therapeutic optimization. HRQoL not only affects the patients but also it affects the patients' family members or caregivers. ${ }^{14,15}$ Its well-known that increasing age and lower educational level leads to poor asthma control requires hospital admissions and were significant with low HRQoL scores. ${ }^{16}$ It was also found that the patients with higher education level have better quality of life in regards to symptoms of asthma. This is due to the higher level of knowledge and awareness about the illness, the ability to identify, manage and treat their symptoms in a fast and efficient way compared to patients with lower knowledge on asthma. Through education, higher number of patients tends to benefit from the ability to follow or read instructions and the ability to understand their health needs. ${ }^{17} \mathrm{~A}$ systematic review on health literacy and health outcomes found that patients with lower health literacy had poorer health-related knowledge and poor ability to interpret the instruction on medication labels, thus leading to non-compliance to the asthma medications. ${ }^{18,19}$ This often results in increased hospitalizations and emergency care. The factors that have major effects on the HRQoL of asthma patients in the symptoms domain of the AQLQ are the age of the patients and lack of education. It's also confirmed that the age and education level of patient is an influencing factor in their HRQoL. In this case, as the age of patient increases, their quality of life in regards to asthma symptoms decreases which can be correlated to the aging processes of respiratory system as the patients' age affects the clinical presen- 
Table 3: Correlation between sociodemographic factors and various domain of AQLQ.

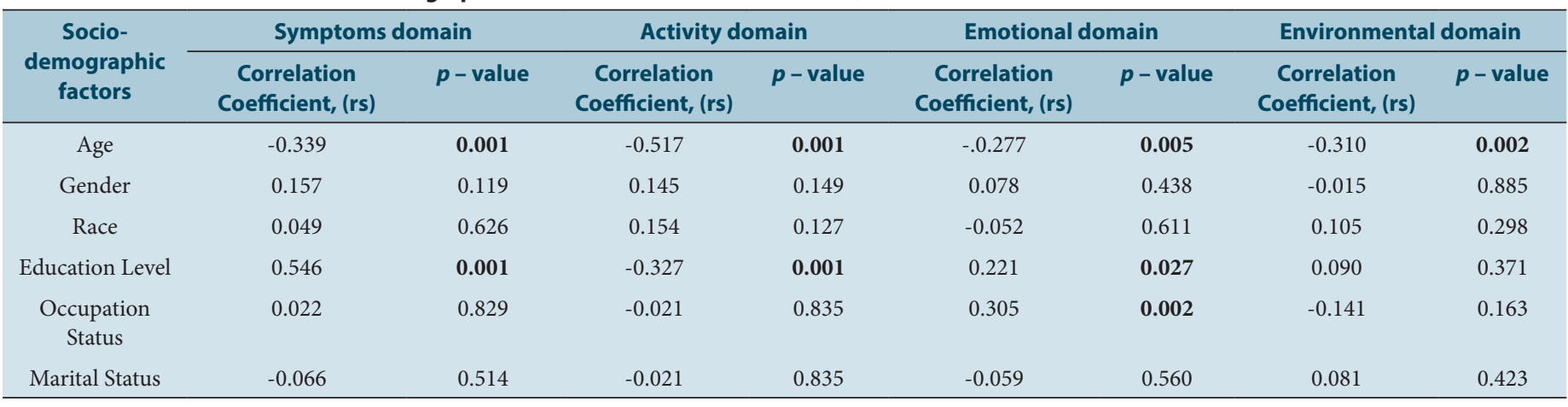

Note: $p<0.05$ indicates the significant Correlation between the sociodemographic factors and various domains performed by Spearman's linear test

tation during asthma. Furthermore, slower body recovery process and longer healing time are often associated with elderly patients compared to younger asthma patients although appropriate asthma medication is prescribed. When the asthma symptoms are not recognized appropriately, they may remain untreated, likely worsening and creating very serious health risks affecting the patients HQRoL. Analysis of the activity limitation domain of the AQLQ and the influencing sociodemographic factors shows that, as the age of patient increases, the HRQoL decreases. This is because age could be a major determinant in feasibility of daily activities. An elderly patient experiences more difficulties and limitations in performing their daily social and work related activities compared to younger asthma patients. Moderate activities such as climbing stairs, gardening and house chores could cause the symptoms to worsen and totally limit their activities. It was underlined that elderly asthma patients have a lower HRQoL and severe limitation in their daily activities. ${ }^{20,21}$ Evidences suggests that quality of life decreases with increases in the age of patients. ${ }^{22}$ These differences were due to the reduction of muscle strength in both upper and lower limbs and changes in body-fat percentage, flexibility and endurance between young and the elderly asthma patients. ${ }^{23}$ Another correlation was found between the education level of asthma patients and activity limitation domain of AQLQ. Patients with college/university qualification had a significantly lower quality of life compared to patients with primary and secondary level of education. This contradicts with the case of symptoms domain; where the higher quality of life was associated with patients having better education level such as those graduated from colleges or universities. This is mainly due to working lifestyle experienced by the patients. Patients with higher education level are mostly the ones working as professionals or experts in their specialized fields. Therefore, they tend to be involved in a lot of physical movements and long working hours, which will eventually limit their activities as long term consequences of asthma. ${ }^{24}$ Emotional domain of the AQLQ has significantly affected the factor, age of the patient. It can be deduced that as the age of patient increases, their emotional becomes more unstable and greatly affected by their asthmatic condition. Old age is often portrayed as a time of rest, reflection and opportunities to do things that were put off while raising families and pursuing careers. ${ }^{25}$ Unfortunately, late-life events such as chronic medical condition like asthma can take a heavy toll on an aging person's emotional well-being. ${ }^{26}$ Asthma with severe symptoms increases as the age increases and it could greatly affect the patients emotions as they constantly become more worried and anxious about worsening health conditions. ${ }^{27}$ Besides that, the sociodemographic factors such as education level and patients occupation status also affect the AQLQ of emotional domain. Higher education level and higher occupation status enables the patient to be more stable emotionally and increases the HRQoL. Patients with bronchial asthma who have low level of education suffer from poor quality of life. ${ }^{28}$ This is also been proved that quality of life is better in patient with higher income status and education level ${ }^{29}$ and is further supported by the research which states that there is a larger limitation in emotional quality of life who has lower education..$^{30}$ Education gives a positive impact on health and mental status. It helps the individual to better decision making and avoiding stressful situations. ${ }^{31}$ Other than that, occupation status is also one of the contributing factors on increased quality of life. Employed patients are found to have better quality of life compared to unemployed patients. This is mainly associated to socioeconomic status of the patients, which influences their financial resources in treating asthma. ${ }^{32}$ Findings about the effect of occupation on health show that the unemployment or inappropriate occupation leads to increased stress, physiological changes and decreased health. In regards to this study it's found that patients often experience poor socioeconomic status and major psychological distress due to the lack of proper job or career in their life. ${ }^{33,34}$ This could be a major contributing factor on the impairment of their quality of life, as experienced by the unemployed patients. Similar results were expressed in an earlier study on the influence of sociodemographic factors on the HRQoL of asthma patients ${ }^{6}$ and revealed that the professional activity of the patients is a contributing factor in their HRQoL. Another reason that can be associated with this, is the higher socioeconomic status achieved by individuals with higher qualifications. People who are able to achieve higher income status are most likely to afford to live in neighbourhood that provides greener environmental space such as recreational parks, lakes, sidewalks and other environmental friendly places to enable residents to walk, cycle and exercise. ${ }^{22}$ Thus, this healthy environment would definitely reduce the risk of environmental pollution on asthma patients. The health benefits of green space for young, elderly and lower income populations have been documented in urban environments. In our study it's revealed that the age and education level are the predominating factors that affect the environmental domain of AQLQ. This indicates that as the age of patient increases, their quality of life in regards to environments decreases, which means they are severely affected from the environmental condition around them. These environmental conditions emphasize on trigger factors of asthma such as dust, air pollutions, pollens and even furs of their own pets such as dogs and cats. ${ }^{35}$ The deterioration in physiologic, biochemical, immunologic and homeostatic parameters, which affects their ability to defend against environmental stresses makes the elderly more sensitive. ${ }^{36}$ It was also found that patients with higher education have better quality of life in regards to the environmental domain compared to patients with low education level. A similar result was suggested that education plays a big role on quality of life in patients with asthma and this is agreed widely among the researchers claiming that the level of education increases along with level of quality of live in entire population and all groups. ${ }^{37,38}$ Highly educated patients are more aware of the untoward effects from environment that could worsen their asthma condition and this knowledge contributes mainly due to their capability to understand facts on asthma. ${ }^{39}$ Our findings implicates that it is important to know the attributing factors related to education which plays a crucial role for improving the HRQoL of asthma patient. 


\section{CONCLUSION}

This study shows that sociodemographic factors such as age, education level and occupation status of the patients has an impact on all the domains of quality of life and in conclusion it's revealed that predominantly higher education plays a pivotal role in HRQoL and we believe that it can be improve by reinforcing health education.

\section{Ethics}

All aspects of the study protocol, including access to and use of the patient clinical information were authorized by the ethics committee and strictly adhered to the regulations. Ethical permission was obtained from Ethics committee of KPJ Healthcare University College (Reference No: KPJUC/RMC/BPH/EC/2017/96)

\section{ACKNOWLEDGEMENT}

The authors would like to thank Professor Elizabeth Juniper and Mrs. Jilly Styles, Qoltech - Measurement of Health-Related Quality of Life and Asthma, Bosham, West Sussex, P018 8NA, UK for providing and permitting us to apply the HRQoL questionnaire (Mini Asthma Quality of Life Questionnaire (Mini AQLQ).

\section{CONFLICT OF INTEREST}

The authors declare no conflicts of interest.

\section{ABBREVIATIONS}

HRQoL: Health-related quality of life; Mini-AQLQ: Mini-Asthma Quality of Life Questionnaire; KCIS: KPJ Clinical Information System.

\section{REFERENCES}

1. Costa DD, Pitrez PM, Barroso NF, Roncada C. Asthma control in the quality of life levels of asthmatic patients' caregivers: A systematic review with metaanalysis and meta-regression. J Pediatr. 2019;95(4):401-9.

2. Gregory M, James K. Expert Panel Report 3 (EPR-3): Guidelines for the Diagnosis and Management of Asthma-Summary Report 2007. J Allergy Clin Immunol. 2007;120(5):S94-138.

3. Holland WW. Chronic respiratory diseases. J Epidemiol Community Heal. 1993;47(1):4-5.

4. Foon FL. Asthma poorly managed among Malaysian sufferers-Nation. The Star Online. 2016;2016(5):2-3. https://www.thestar.com.my/news/nation/ 2016/05/26/asthma-poorly-managed-among-malaysian-sufferers/ \#SipDOBRrV9VJmmph.99.

5. Noor SMN, Khor GL, Suzana S, et al. The Third National Health and Morbidity Survey (NHMS III) 2006: Nutritional status of adults aged 18 years and above. 23rd Sci Conf Nutr Soc Malaysia. 2008;14(2):1-87.

6. Szynkiewicz E, Filanowicz M, Graczyk M, et al. Analysis of the impact of selected socio-demographic factors on quality of life of asthma patients. Postep Dermatologii i Alergol. 2013;30(4):218-25.

7. Katz PP, Yelin EH, Eisner MD, Blanc PD. Perceived control of asthma and quality of life among adults with asthma. Ann Allergy, Asthma Immunol. 2002;89(3):251-8.

8. Andersen RM, Davidson PL, Ganz PA. Symbiotic relationships of quality of life, health services research and other health research. Qual Life Res. 1994;3(5):365-71.

9. Mroczek B, Kurpas D, Urban M, Sitko Z, Grodzki T. The influence of asthma exacerbations on health-related quality of life. In: Advances in Experimental Medicine and Biology. 2015;873:65-77.

10. Rosenwasser L, Hossny E, El-GamalY, Caraballo L, Casale T. Severe asthma and quality of life. World Allergy Organ J. 2017;10(1):1-8.

11. Lundgren J, Axelsson M, Lötvall J, Emilsson M, Torén K, Brink E. Personality, adherence, asthma control and health-related quality of life in young adult asthmatics. Respir Med. 2009;103(7):1033-40.

12. Daniel WW. A foundation for analysis in the health sciences. Biostat Toronto, John Wiley Sons. 1991;209-15

13. Juniper EF, Guyatt GH, Ferrie PJ, Griffith LE. Measuring Quality of Life in Asthma. Am Rev Respir Dis. 1993;147(4):832-8.
14. Spratt H, Melethil S, Ho S, Goldblum RM, Acharya VS, Smith KE. Impact of Asthma Control on Health Related Quality Of Life of Affected Children and their Caregivers. J Allergy Clin Immunol. 2017;139(2):AB57.

15. Sheikh S, Pitts J, Sheikh M, Ryan-Wenger N. Impact of Age of the Child on Quality of Life of Families of Children With Asthma. Chest. 2017;152(4):A840.

16. Gonzalez-Barcala FJ, DeLa Fuente-Cid R, Tafalla M, Nuevo J, Caamaño-Isorna F. Factors associated with health-related quality of life in adults with asthma. A cross-sectional study. Multidiscip Respir Med. 2012;7(5):1-10.

17. Ponte EV, Petroni J, Ramos DCB, Pimentel L, Freitas DN, Cruz AA. Perception of asthma control in asthma patients. J Bras Pneumol. 2007;33(6):635-40.

18. Rosas-Salazar C, Apter AJ, Canino G, Celedón JC. Health literacy and asthma. J Allergy Clin Immunol. 2012;129(4):935-42.

19. Kaplan R, Spittel MDD. Population Health: Behavioral and Social Science Insights. Understanding the Relationship Between Education and Health 2015:1-431. https://www.ahrq.gov/professionals/education/curriculum-tools/ population-health/satterfield.html\%0Ahttps://www.ahrq.gov/cpi/about/index. html.

20. Lindner K, Panaszek B, Machaj Z. Diagnostic Distinctions of Bronchial Asthma in the Elderly. Polish Pneumonol Allergol. 2008;76(4):246-52.

21. Oraka E, King ME, Callahan DB. Asthma and serious psychological distress: Prevalence and risk factors among US adults, 2001-2007. Chest. 2010;137(3):609-16.

22. Jones SC, Iverson D, Burns P, Evers U, Caputi P, Morgan S. Asthma and ageing: An end user's perspective - the perception and problems with the management of asthma in the elderly. Clin Exp Allergy. 2011;41(4):471-81.

23. Milanovic Z, Pantelic S, Trajkovic N, Sporis G, Kostic R, James N. Age-related decrease in physical activity and functional fitness among elderly men and women. Clin Interv Aging. 2013;8:549-56. [Clin Interv Aging. clin interv aging. 2014;9:979.]

24. Folgering H, DenBoom GV, Dompeling E, Weel CV, Schayck CPV, Rutten MPMH. The Influence of an Inhaled Steroid on Quality of Life in Patients With Asthma or COPD. Chest. 2008;107(5):1199-205.

25. Wang KY, Wu CP, Tang YY, Yang ML. Health-related quality of life in Taiwanese patients with bronchial asthma. J Formos Med Assoc. 2004;103(3):205-11.

26. Gonzalez-Barcala FJ, DeFuente-Cid RL, Tafalla M, Nuevo J, Caamano-Isorna F. Factors associated with health-related quality of life in adults with asthma: A cross-sectional study. Multidiscip Respir Med. 2012;7(5):32.

27. Melgert BN, Ray A, Hylkema MN, Timens W, Postma DS. Are there reasons why adult asthma is more common in females?. Curr Allergy Asthma Rep. 2007;7(2):143-50.

28. Chen $\mathrm{H}$, Gould MK, Blanc PD, et al. Asthma control, severity and quality of life: Quantifying the effect of uncontrolled disease. J Allergy Clin Immunol. 2007;120(2):396-402.

29. Ferreira LN, Brito U, Ferreira PL. Quality of life in asthma patients. Rev Port Pneumol. 2010;16(1):23-55.

30. Bousquet $J$, Knani $J$, Dhivert $H$, et al. Quality of life in asthma: I. Internal consistency and validity of the SF- 36 questionnaire. Am J Respir Crit Care Med. $1994 ; 149(2): 371-5$

31. Martinez TY, Pereira CAC, DosSantos ML, Ciconelli RM, Guimarães $S M$ Martinez JAB. Evaluation of the Short-Form 36-Item Questionnaire to Measure Health-Related Quality of Life in Patients With Idiopathic Pulmonary Fibrosis. Chest. 2000;117(6):1627-32

32. Law M, Steinwender S, Leclair L. Occupation, health and well-being. Can J Occup Ther. 1998;65(2):81-91.

33. Wang KY, Wu CP, Tang YY, Yang ML. Health-related quality of life in Taiwanese patients with bronchial asthma. J Formos Med Assoc. 2004;103(3):205-11.

34. Ringsberg KC, Wiklund I, Wilhelmsen L. Education of adult patients at an "asthma school": Effects on quality of life, knowledge and need for nursing. Eur Respir J Off J Eur Soc Clin Respir Physiol. 1990;3(1):33-7.

35. Stewart AL, Greenfield S, Hays RD, et al. Functional Status and Well-being of Patients With Chronic Conditions: Results From the Medical Outcomes Study. JAMA J Am Med Assoc. 1989;262(7):907-13.

36. Guyatt GH. Measuring Health-Related Quality of Life. Ann Intern Med. 1993;118(8):622.

37. Uchmanowicz B, Panaszek B, Uchmanowicz I, Rosinczuk J. Sociodemographic factors affecting the quality of life of patients with asthma. Patient Prefer Adherence. 2016;10:345-54.

38. Heethal JP, Khine KM, Kenneth WCF, et al. A survey on the quality of life in patients with bronchial asthma in an outpatient clinic in Malaysia. $\mathrm{Br} \mathrm{J}$ Med Med Res. 2014;4(5):1187-94.

39. Apter AJ, Reisine ST, Affleck G, Barrows E, Zuwallack RL. The influence of demographic and socioeconomic factors on health-related quality of life in asthma. J Allergy Clin Immunol. 1999;103(1):72-8.

Article History: Submission Date : 16-08-2019; Revised Date : 24-09-2019; Acceptance Date : 01-10-2019.

Cite this article: Chellammal HSJ, Arumugam D, Menon BVV, Menon SMM, Faizal SBM. Sociodemographic Factors and its Impact on Health Related Quality of Life (HRQoL) among Adult Asthma Patients in a Private Specialist Hospital in Malaysia. J Young Pharm. 2019;11(4):404-9. 